\title{
Improving the Enterprise Activities Based on the Lean Technologies
}

\author{
Tatyana L. Sergeeva 1[ORCID 0000-0001-6818-0405], \\ Yanina V. Patturi ${ }^{1 *[}$ ORCID 0000-0001-8554-1567], \\ Dmitriy S. Petrov 2[ORCID 0000-0003-0545-1022]
}

\author{
${ }^{1}$ Yaroslav-the-Wise Novgorod State University, Veliky Novgorod, Russia \\ ${ }^{2}$ LTD "PRODO Management”, Moscow, Russia \\ Yanina.Patturi@novsu.ru
}

\begin{abstract}
Intense competition and innovative activity characterize the modern business industry. In order to achieve high efficiency of business processes, remain competitive and earn profit, provide customers with quality products within the shortest time possible, the company needs to optimize production, timely eliminate losses and efforts that do not bring results. The relevance of the research topic is beyond doubt, since the improvement of the enterprise's activities at all its stages is facilitated by introducing methods and tools of lean manufacturing, which are currently widely used. Based on studying the practical experience of using lean tools by Russian and foreign organizations in various sectors of the economy, this study presents the features and benefits of the concept of lean manufacturing, as well as the problems associated with its use. The article presents the results of a pilot project on introducing lean technologies at a meat-processing enterprise in order to optimize the work of a canning shop. The project focuses on applying basic lean methods and tools: a system for organizing a safe and efficient workplace (5S), value stream mapping, work standardization, quick readjustment (SMED) and a system for collecting proposals for improvements (Kaizen). The current state of the pilot stream has been assessed in the work in order to identify existing losses and problems; the main directions for optimizing the value stream, eliminating identified problems and minimizing losses have been developed; the results of implementing measures to introduce lean technologies in the canning shop have been evaluated. The dynamics of the enterprise performance key indicators confirms the effectiveness of the lean production system and the need to replicate positive experience to other flows and processes operating at the enterprise.
\end{abstract}

Keywords: lean manufacturing, lean technologies, business efficiency, value, losses

\section{INTRODUCTION}

Systemic changes in the economy, scientific and technological progress have caused large-scale changes in the industry, for which the issues of developing and implementing tools that ensure the sustainable enterprise development have become increasingly relevant. One of such tools allowing to ensure sustainable long-term development is the concept of lean manufacturing.

The issues of developing and implementing of lean technologies are of scientific interest and are becoming increasingly relevant. This concept is based on the production optimization due to reducing losses, finding and eliminating unnecessary processes that do not bring or reduce the value added to consumers.

The results of studies [1-7] confirm that the introduction of lean manufacturing at enterprises leads to sustainable business development and is one of the foundations for positive changes in organizations in various sectors of the economy. The use of lean technologies makes it possible to achieve high labour productivity and achieve a significant economic effect.

In particular, the use of lean manufacturing tools contributes to the emergence of organizational and economic benefits: 
- reducing the cost of storing inventories by reducing their level;

- reducing rejects and alterations;

- improving the quality of products (works or services), and, consequently, increasing consumer loyalty;

- reducing deadlines in production and delivering products to consumers;

- reducing costs by reducing the number of non-productive work on transferring and storing goods, as well as by reducing production areas;

- reducing the number of activities in progress;

- reducing equipment readjustment time;

- increasing the level of labour safety;

- increasing the working capital turnover.

The use of lean manufacturing tools in an organization contributes to increasing the level of profitability, as well as increasing the level of customer satisfaction and achieving competitive advantages.

According to [8], the functioning of lean tools together in all the enterprise departments enhances cost optimization and gives a synergistic effect, expressed both in production and mixed effects, both in internal and external ones, as well as in indirect effects. Moreover, it is the introduction of a set of tools that has an impact on the company economic performance.

In [9], the need to implement changes in introducing lean manufacturing (Leantransformations) in the form of projects is pointed out, as well as the advantages of project management when introducing lean technologies and the emergence of a multiplier effect when such transformations are carried out at industrial enterprises.

Lean systems have their own strengths and weaknesses, their own characteristics that need to be taken into account. They are highly effective in the presence of a stable environment, predictable demand, high production volume and limited diversity requirements. However, in modern conditions, when markets are more dynamic and unpredictable, product life cycles are shorter, innovation introduction rates are higher, mass markets are divided into niche markets, product standardization is replaced by the need for mass production to order, lean technologies are not able to solve the tasks assigned to them, and even at lower cost [10].

As practice shows, the experience of using a lean system at enterprises is not always successful. Sometimes, due to problems in the business environment, as well as due to non-complex implementation, subjective errors, flaws in the management system, the use of the lean concept does not bring significant results [11].

In a number of works [12-14], the authors point out the main problems of implementing lean technologies, represented by external factors and internal limitations:

- lack of a long-term implementation planning system;

- lack of appropriate corporate culture;

- lack of specialists in the field of production systems;

- low involvement of personnel in the process of change and their resistance to change;

- lack of understanding of the order of implementing lean manufacturing individual tools;

- expecting quick results;

- insufficient attention and participation of the enterprise management, etc.

Many of these problems are caused by insufficient theoretical training of employees at different levels, senior managers" "isolation" from practice, from manufacturing areas and value creation places, as well as difficulties in the interaction between the enterprise different departments [13].

It should be noted that the success of the lean technologies implementation also depends on the companies' leaders, their leadership qualities and involvement, an established interaction and communication system, a clear understanding of the system of the value creation process indicators, and competence in the business processes implementation. Culture, leadership, involvement and motivation should be the main guidelines for the lean manufacturing implementation. 


\section{MATERIALS AND METHODS}

The purpose of the study is to assess the possibility of improving the enterprise activities through introducing lean manufacturing tools.

The implementation of this goal involves solving the following tasks:

1) assessing the current production state in order to identify losses and problems in the pilot stream;

2) developing the main directions for optimizing the value stream, eliminating identified problems and minimizing losses;

3) evaluating the results of implementing measures to introduce lean technologies in the canning shop.

The pilot project, developed and implemented at the enterprise under study, was focused on the use of basic lean methods and tools:

- $5 \mathrm{~S}$ - a system for organizing a safe and efficient workplace;

- value stream mapping (VSC) is a key tool for visualization and analysis of material and information flows, which allows us to identify losses and potential for improvements in the manufacturing process;

- work standardization - allows us to accurately describe each production stage, fix and document the solution found, which allows us to completely solve the existing problem; includes making changes to regulatory documents, manufacturing plans, creating standard operating procedures, etc. [15];

- quick readjustment (SMED);

- a system for collecting proposals for improvements (PFI) of the process (Kaizen).

The following methods were used to collect and analyze baseline information, as well as to identify problems, analyze and find their root causes:

- 5 "Why" and 4W2H question techniques structured brainstorming methods that allow us to study and describe the problem in detail by consistently setting specific questions and detailed answers to them within the framework of the task;
- timing and Spaghetti diagram - are necessary for fixing and measuring the duration of process operations, as well as the real ways of moving products within the value stream, respectively;

- Questionnaire Observation Sheets to help structure the information collection;

- Ishikawa diagram - a graphical way to study and determine the most significant cause-andeffect relationships between factors and consequences in the problem under study.

\section{RESULTS}

The enterprises' desire to remain competitive and earn profits, to provide customers with quality products within the shortest time possible - all these make it necessary to optimize production, eliminate losses and those efforts that do not bring the expected result.

The modern meat-processing enterprise "Velikonovgorodsky Myasnoy Dvor" JSC (hereinafter - "VNMD" JSC), which includes a full cycle of raw meat processing, is no exception. In 2019, the organization under study became a participant in the "Labour Productivity" national project, the purpose of which is to increase labour productivity and increase profits without unnecessary investments.

At "VNMD" JSC, a project to introduce lean manufacturing was implemented in a canning shop. The production line for "stewed pork" canned meat (hereinafter referred to as canned food) was chosen as a pilot one, and the canned meat packaging area became the reference site. The main customers for canned food are federal retail chains, the Armed Forces of the Russian Federation, and the Federal Service of the Troops of the National Guard.

The choice of an optimized pilot stream is due to frequent delays in the delivery of products to customers due to unmanaged stocks of work in progress, downtime and expectations, low accuracy of a shift task operational planning, which led to the payment of fines and penalties.

The production of any product is a complex multi-step process during which the product is transferred between the warehouse and shops, awaits processing, shipment, etc. In order to find hidden reserves and opportunities for optimizing 
production, it is necessary to see the entire production process as a whole: from the customer's order to the shipment of finished goods.

In the process of implementing the project to improve "VNMD" JSC activities using lean technologies, a map of the current value stream has been developed, which has made it possible to visualize and analyze the entire value stream, identify losses and problems in production.

In total, more than 60 problems have been identified, the main ones of them are:

- labour-intensive process of inserting cardboard circles under the jar lid turnkey;

- labour-intensive process of assembling corrugated boxes;

- the duration of the process of the canned food capping line readjustment;

- frequent readjustments and washing of the line, associated with a large range of products manufactured per shift;

- high labour intensity at the labeling site due to the need to turn the jar over by hands;

- long collection of applications for a label, corrugation at a warehouse, etc.

All these problems affect the total lead time (LT) for the canned meat manufacture. When assessing the current state, it was more than 603 minutes.

Value stream optimization involves not only the study of material and information flows and their visualization, but also the development of a target value stream map, as well as drawing up an action plan to eliminate identified problems, minimize losses by eliminating factors that increase LT.

As the main directions of flow optimization the following ones have been chosen:

- reducing the volume of work in progress;

- reducing lead time;

- increase in production;

- improving the accuracy of shift task operational planning.

It should be noted that in the reference area (packaging area for canned meat) a low efficiency of the line (about 50\%) has been revealed, associated with the need to replace labels and carry out washes, replace nets, and lack of orders from the commercial supply service. In order to eliminate these problems, standards have been developed for replacing labels, washing and disinfecting equipment, and a lean tool has been introduced to reduce losses during equipment readjustment and retooling (SMED). Also at this site, it is planned to continue to use the system for collecting proposals for improvements from employees; as well as to improve the standards of work with the commercial supply service, contributing to the organization of a balanced load of equipment.

The use of lean technologies has made it possible to achieve individual results in the reference section of canned meat packaging. So, due to the introduction of a system of the working space rational organization $(5 \mathrm{~S}), 20 \%$ of production space has been freed up. In addition, the use of tools such as mapping, SMED, 5S, standardized work and suggestions for improvements has led to an $18 \%$ reduction in work in progress (from 354 million rubles to 290 million rubles), as well as an increase in average hourly output by $40 \%$ compared to this indicator level in 2019. At the same time, the lead time has been reduced by $20 \%$ (by 12 minutes for one batch of $1170 \mathrm{~kg}$ ), which has made it possible to release 2 employees per shift (redirect them to another work site), reducing the number of employed workers by $29 \%$.

When developing a project to improve the activities of "VNMD" JSC based on the introduction of lean manufacturing tools in the pilot stream of canned meat production, a number of improvements have been proposed. Let us present the results of implementing some of them:

1) Due to the high level of labour intensity of the corrugated box assembly process, the format of the box used has been changed - a transition to the "autobottom" box has been made, and 6 tables for assembling corrugated boxes equipped with fasteners for tools have been manufactured and installed. As a result of implementing these improvements, there has been a reduction in the time of box assembly by $38 \%$ per shift, more convenient workplaces for employees have been organized, losses associated with unnecessary movements of employees have been eliminated, and the lead time has been reduced by 10 minutes. In addition, 11762 rubles per month have been released from the 
piecework wage fund (PWF), which has allowed a slight increase in the salary of stackers.

2) To eliminate losses caused by excessive processing at the labeling site, negotiations have been held with customers and a decision to eliminate the operation of inserting cardboard circles under the jar lid turnkey has been made, as a result of which the salary of the stacker-packer has increased due to the distribution of the released PWF in the amount of 14800 rubles per month for the workers remaining at the site. In addition, the implementation of this improvement has saved 84000 rubles per month for the purchase of cardboard circles, and also has led to a reduction in lead time by 12 minutes.

3) As a result of the value stream mapping, significant losses ( 1 hour per shift) have been identified due to the long and frequent readjustment of the capping line due to the wide range of products produced per shift. This problem has been eliminated by the development and implementation of standards for shift maintenance of equipment (SME), equipment readjustment standards, as well as checklists for equipment maintenance. The implementation of these measures has led to a reduction in the time of one equipment readjustment from 10 to 8 minutes (by 20\%) and a decrease in the number of readjustments per shift by $17 \%$, which has made it possible to increase the production time of the line and additionally produce 200 cans of products in the amount of 10800 rubles.

4) An analysis of the canned meat production has shown that the process of manually turning cans at the labeling site is very labour-intensive and requires the required number of employees ( 7 people per shift). The use of one of the lean tools - Kaizen suggestions (collection of suggestions for improvements from employees) - has made it possible to manufacture and install an automatic can turner on the canned food labeling line. The main result is an increase in work efficiency, in particular, an increase in labour productivity by 4.4 n.-jars / man-hour and the release of 185200 rubles from the piecework wage fund (due to a $29 \%$ reduction in the number of people employed in this area), which has made it possible to increase the average salary of other workers.

5) As a result of the audit, overstocking of finished goods (500 thousand cans) has been identified and sold, which has made it possible to solve the problem of lack of the warehouse space.
The volume of work in progress has decreased by $50 \%$, the proceeds from the sale has amounted to 27.5 million rubles.

6) The development and implementation of the printed form of the shift task have helped to eliminate the daily time spent $(7$ minutes $)$ for its clarification and have also eliminated the loss of information by the work performers (mince, spice compilers, labeling site operators). The standard introduction has made it possible to increase the production time and additionally manufacture products worth 7470.9 rubles per shift.

The implementation of all measures to improve "VNMD" JSC activities using lean technologies has made it possible to obtain the following results:

- the time of the canned meat production process has been reduced by $26 \%$;

- production volume has increased by $64 \%$;

- the average workers' wage has increased by $22 \%$ (by 6,537 rubles per month);

- the volume of work in progress has decreased by $50 \%$;

- increase in labour productivity has amounted to $16 \%$.

\section{DISCUSSION}

A significant number of studies have been devoted to the problems of using the concept of lean manufacturing at enterprises. However, equally often, the authors demonstrate positive experience and significant results of lean technologies introduction in the activities of both Russian and foreign companies.

As a result of participation in the "Labour Productivity" national project and the lean manufacturing tools introduction in order to improve its activities, "VNMD" JSC has already, within the pilot stream, managed to reduce the lead time, reduce the volume of work in progress, and increase labour productivity. The results achieved confirm the effectiveness of the lean manufacturing system and the need to replicate positive experience to other flows and processes operating at the enterprise.

\section{CONCLUSION}

The article presents the results of a pilot project on the introduction of lean technologies at 
"VNMD" JSC meat processing enterprise in order to improve the work of the canning shop.

The article substantiates the choice of the pilot stream, presents the main problems and losses identified in the process of constructing the current value stream map. The development of the main directions for optimizing the value stream and the implementation of measures to improve the enterprise's activities has made it possible to eliminate the identified problems and minimize losses, as evidenced by the assessing the results of implementing the project on introducing lean technologies in the canning shop.

And although the concept of lean manufacturing has shown quite good results when being implemented at the researched enterprise, it is worth noting that this is a painstaking and serious work of both of the enterprise's head and each team member.

The results of the project are of high practical importance for the enterprise under study.

\section{AUTHORS' CONTRIBUTIONS}

The concept of the study, writing the theoretical part of the article - Tatyana L. Sergeeva. Writing a practice-oriented part of the text - Dmitriy S. Petrov. Critical analysis, formulation of conclusions and article editing - Yanina V. Patturi.

\section{REFERENCES}

[1] M.A. Nurzhasarova, L.T. Sarttarova, D.B. Dikenova, M. Mandidat, Z.K. Adambekova, "Principles of implementation of lean production at sewing companies", Proceedings of Higher Education Institutions. Textile Industry Technology, 2019, vol. 5(383), pp. 187-191. (In Russ.).

[2] J. Furman, T. Malysa, "The use of lean manufacturing (LM) tools in the field of production organization in the metallurgical industry", Metalurgija, 2021, vol. 60(3-4), pp. 431-433.

[3] T. Anosike, K. Alafropatis, J.-A. Garza-Reyes, A. Kumar, S. Luthra, L. Rocha-Lona, "Lean manufacturing and internet of things - A synergetic or antagonist relationship?", Computers in Industry, 2021, vol. 129(23), p. 103464 .

DOI:

\subsection{6/j.compind.2021.103464}

[4] I.A. Andreev, "The experience of lean manufacturing in defense industry", Journal of «Almaz - Antey» Air and Space Defence Corporation, 2017, vol. 3, pp. 27-36. DOI: 10.38013/2542-0542-2017-3-27-36

[5] J. Antony, M. Kumar, "Lean and Six Sigma methodologies in NHS Scotland: an empirical study and directions for future research", Quality Innovation Prosperity, 2012, vol. 16(2), pp. 19-34. DOI: 10.12776/qip.v16i2.55

[6] Z. Radnor, R. Johnston, "Lean in UK Government: Internal Efficiency or Customer Service", Production Planning and Control: The Management of Operations, 2012, vol. 24910(11), pp. 903-915. DOI: $10.1080 / 09537287.2012 .666899$

[7] L.G. Kirillova, E.V. Bardasova, "Management approaches for the implementation of technology of lean production at the enterprises of the service sphere", Economics and management: problems, solutions, 2019, vol. 11(3), pp. 95-99. (In Russ.).

[8] T.G. Dolgopyatova, Ye.V. Shilyaeva, "Network Effects of Lean Production Implementation", The Manager, 2017, vol. 4(68), pp. 14-23. (In Russ.).

[9] T.A. Suetina, M.Y. Odinokov, D.M. Safina, "Benefits of project management at lean manufacturing tools implementation", Asian Social Science, 2014, vol. 10(20), pp. 62-66. DOI: $10.5539 /$ ass.v10n20p62

[10] S.A. Bratchenko, "Lean production in Russia: theory and practice", Moscow University Economics Bulletin, 2018, vol. 3, pp. 146-158. (In Russ.).

[11] T.G. Dolgopyatova, Ye.V. Khomyakova, "The Implementation of Lean Production System: Incentives, Effects and Problems. A Case of KAMAZ Publicly Traded Company", Russian Management Journal, 2016, vol. 14(2), pp. 4976. (In Russ.).

[12] G.E. Bazhenov, A.V. Dyachkova, "Issues of implementation of lean manufacturing concept at Russian enterprises", Business. Education. Right, 2016, vol. 3(36), pp. 14-20. (In Russ.).

[13] N.A. Markova, D.A. Markov, "Problems in 
implementing lean production at enterprises", The Manager, 2018, vol. 9(6), pp. 40-48. (In Russ.). DOI: 10.29141/2218-5003-2018-9-6-4

[14] S.M. Kazantseva, "Problems related to the implementation of lean production within the Russian enterprises", Creative Economy, 2014, vol. 12(96), pp. 90-98. (In Russ.).

[15]E.V. Loginova, S.A. Shchegoleva, "Analysis methods and tools of lean manufacturing", Information and economic aspects of standardization and technical regulation, 2021, vol. 1(59), pp. 22-27. (In Russ.). 